\title{
A Study of the Indoor Walking Navigation System for Patients with Early-stage Alzheimer's Disease
}

\author{
Yung-Ching Liu ${ }^{1 *}$, Yang-Kun Ou ${ }^{1}$, Sung-Nung Lin ${ }^{1}$, Chen-Wen Fang ${ }^{2}$ \\ ${ }^{1}$ Department of Industrial Engineering and Management, National Yunlin University of Science and Technology, Yunlin, \\ Taiwan. \\ 2 Department of Neurology, National Taiwan University Hospital (Yunlin Branch), Yunlin, Taiwan. \\ \{liuyc \& g9621802 \& g9621804\}@yuntech.edu.tw, N10127001@yuntech.edu.tw
}

\begin{abstract}
We explored the effect and the difference between types of electronic map, paper map and colored lines guide on the wayfinding abilities of Alzheimer's disease (AD) patients. Fifty-six normal control (NC) subjects, nineteen mild cognitive impairment (MCI) patients and thirty patients with Alzheimer's disease (AD) were recruited to participate in this study. Based on a virtual maze with 3Dmax and an interface with Virtools, our results showed that the wayfinding abilities were worse in the AD group compared with the MCI group and normal aged participants. However, with the support of track-up map and colored lines guide, the AD group and MCI group had similar performance as to normal aged participants. Our study has provided insight to establish future electric navigation maps built for patients with cognition impairment.
\end{abstract}

Index Terms - Alzheimer's Disease, Walking Navigaiton Syetem, Wayfinding, Virtual Environment.

\section{Introduction}

Wayfinding is a dynamic activity in which people process the data or information they receive to predetermine destination through the cognitive abilities of the environment space [1]. In general, normal people can ultimately perform the wayfinding process successfully. However, for people with Alzheimer's disease, getting lost is the most serious problem to both themselves and their families. The prevalence rate of elderly dementia in developed countries is about 5-6\% -Alzheimer's being the most common type of dementia [2, 3, 4]. Related researches has indicated that there are about $89 \%$ of $\mathrm{AD}$ patients who had gotten lost in their familiar environment due to impaired ability of wayfinding [5]. McShane, et al. observed 104 AD patients every 4 months over a long time period. The record showed that there were 43 $\mathrm{AD}$ patients getting lost more than once in 5 years. Furthermore, 5 of the $43 \mathrm{AD}$ patients were getting lost repetitively [6]. The road environment in Taiwan is highly complicated, which causes a high disorientation rate of $\mathrm{AD}$ patients. In addition, the impaired spatial cognitive ability and the hippocampus degradation that accompany AD seriously affects the process of wayfinding. Hippocampus being an important organ in the navigation task, its degeneracy or damage leads to the digression of AD patients [7], and causes serious spatial memory damage simultaneously [8]. Based on the above reasons, the early stage $\mathrm{AD}$ patients would have difficulties in accomplishing wayfinding tasks. Being unable to perform wayfinding successfully is an important characteristic of early stage AD patients. The quality of life would be improved and the cause of the disease would be better understood if the $\mathrm{AD}$ patients enhanced their wayfinding performances through appropriate navigation systems. Thus, the purpose of this study is to analyze wayfinding performances with different kinds of navigation systems used for AD patients. Furthermore, this study is also directed to develop a better navigation system for $\mathrm{AD}$ patients.

Common wayfinding aids provided through the visual sense are listed as the following: (1) Directional label, (2) Guideline label and (3) Identification label [9]. The straying of AD patients was caused by being unable to determine the path direction. In order to achieve direct and simple guidelines to minimize the information process of $\mathrm{AD}$ patients, four kinds of wayfinding aids were designed and examined to explore the most suitable method as the AD patients wayfinding aids in this study. They are: (1) North-up electric navigation map, (2) Trick-up electric navigation map, (3) Colored lines guide and (4) Paper map. Amount of the four wayfinding aids, the paper map used in the current study is a full view map, but both electric navigation maps are small-scale maps. Some related studies have indicated that the full view map lead an efficient guide of routes for routing decision [10]. Thus, many vehicle navigation maps present information with large-scale map. On the other hand, different studies indicate that comparison with the large-scale map (presenting more than 2 blocks) and smallscale map (presenting 1-2 blocks), vehicles have the shorter trip duration with the small-scale map [11].

Two common orientation instructions were north-up map (world-centered) and track-up map (ego-centered) [12]. There are no consistent conclusions on both orientations impacting on spatial cognition amount related studies. But most studies indicate that using north-up map decreases the difficulties in searching and recognizing specific landmark and increases better routing performance $[13,14]$. On the other hand, the tracks demonstrate an advantage on route tracking and direction recognition [13].

In addition to the foregoing wayfinding guidelines tools, the current study takes a colored lines guide into consideration due to its prevalence and usefulness of the route directions in both unfamiliar and complex hospital space $[14,15]$. Colored lines guide is an intuitive wayfinding assist mode and space users can just simply follow the lines without much pressure. As a result, this navigation method won't cause users too much of a burden. 
Considering the insufficient research on the navigation system for $\mathrm{AD}$ patients, this study proposed a walking navigation system for dementia patients, carrying out the wayfinding performance when using electric map display methods with different orientations, paper map, and colored lines guide.

\section{Methods}

\section{A. Participants}

Fifty-six normal control (NC) subjects, nineteen mild cognitive impairment (MCI) patients and thirty patients with Alzheimer's disease (AD) were recruited to participate in this study. AD and MCI patients were recruited from a neurology outpatient clinic at National Taiwan University Hospital, YunLin Branch. Normal control elderly participants were also recruited from Yunlin County. Informed consent forms were read and signed by each participant and the study was approved by the institutional review board ethics committee. $\mathrm{AD}$ and $\mathrm{MCI}$ patients underwent standardized examinations, including Mini-Mental Status Evaluation (MMSE) [16] and Clinical Dementia Rating (CDR) scale [17]. MCI was defined as a CDR of 0.5 , and $A D$ was defined as CDR of 1.0. The mean MMSE values of $\mathrm{AD}, \mathrm{MCI}$, and control groups were $15.08 \pm 4.03,19.42 \pm 4.66$, and $28.36 \pm 1.89$, respectively. Participants completing the experiment were each paid US\$20.

\section{B. Apparatus}

This study used a set of computer software to create an indoor virtual environment to simulating a walking situation in the real world. The indoor virtual environment was used to evaluate the interface design of the walking navigation systems. The experimental scene was created by 3D Studio Max 2011 software to construct a 3D scene model. The size of the scene is $100 \mathrm{~m} \times 50 \mathrm{~m}$, using Virtools 4.0 to set up an interactive interface. In this study, two 15 -inch notebook computers were used to perform this experiment--a notebook computer rendered a 3D virtual environment; the other showed the map of the navigation system.

\section{Experimental Design}

Two factors were involved in this mixed-factorial experiment: subject groups (NC vs. MCI vs. AD; betweensubjects) and navigation maps (north-up vs. track-up vs. colored lines guide vs. paper map ; within-subjects). Each subject completed experiments in 4 different mazes. The complexity (i.e., number of turns) of all the mazes was the same.

The navigation map was divided into four types: 1) North-up map: the upward direction remained north consistently. It would not rotate with the pedestrian. The subject was required to identify the current direction by mental rotation, making it a world-centered reference frame; 2) Track-up map: the map would rotate while the pedestrian changed direction. The upward direction consistently retains the direction of travel. Pedestrians could determine the direction of the next turn without mental rotation, making it an egocentric reference frame; 3 ) Colored lines guide: the subject was instructed to follow one of the three colored lines on the floor to reach the destination (Fig. 1(a)); 4) Paper map: the whole route directions were depicted on the paper (Fig. 1 (b)).

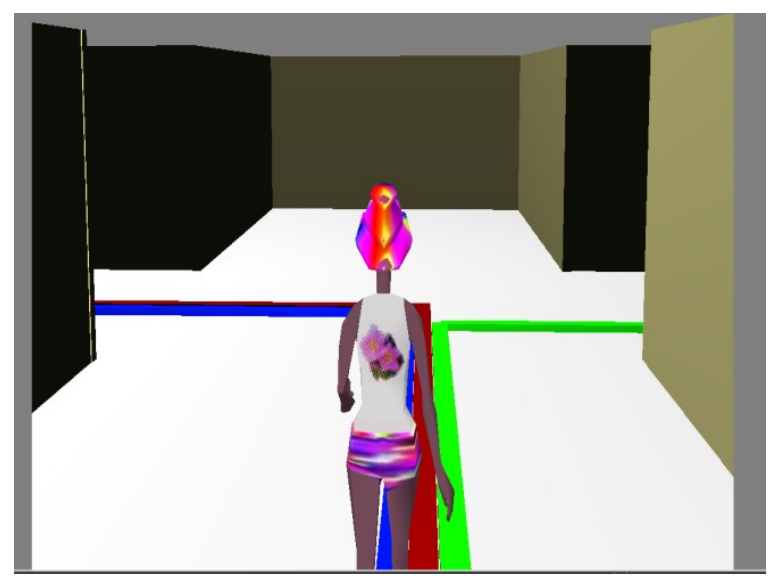

(a)

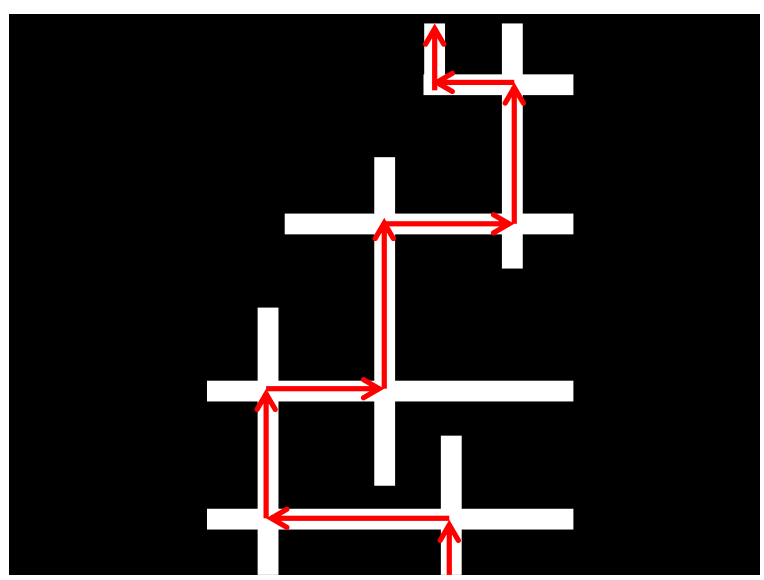

(b)

Fig. 1 Examples of (a) colored lines guide, and (b) paper map with full of turn directions.

Two dependent variables were collected for this study: 1) Number of wrong turns; and 2) Performance time: the time the participant completed the wayfinding task.

\section{Procedures}

Before the start of the experiment, each participant was informed the purpose and the procedure of the study. Subjects were also told to stop at any time if they felt uncomfortable. A consent form was read and signed by each participant before he or she started the experiment.

First, subjects were instructed to preform one simulation exercise before the wayfinding test. They had to be able to give correct instructions and point out the path by gestures and words. We then verified that the subjects were fully aware of the method before the formal experiment. Subjects only needed to provide verbal instructions of "forward," "backward," "turn left," and "turn left" and gestured to the next direction without a need to control the keyboard. The 
experimenter operated the system instead of the subject in order to avoid possible errors due to motor difficulties in some subjects.

Each subject performed wayfinding tests in four different mazes, each with four different navigation systems, namely, track-up map, north-up map, colored lines guide and paper map. Each maze contained seven navigation decision points. Number of wrong turns and performance times were recorded. There was a 5-minute break between each experiment. The total experiment time was about 40 minutes. Subjects were paid after the completion of the experiment.

\section{Results}

\section{A. Performance Time}

The results of ANOVA test indicate that the navigation map types and subject groups had statistically significant main effects on performance time $[\mathrm{F}(3,255)=49.25, \mathrm{P}<0.001$; $\mathrm{F}(2,85)=66.00, \mathrm{P}<0.001$, respectively]. The track-up map (118.31s) and colored lines guide (122.63s) had the shortest performance time, followed by the north-up map (142.21s), and the paper map (169.40s). NC group (109.15s) had the shortest performance time, followed by MCI (132.98s) and AD (172.29s).

The two-way interactions were found for the performance time between the map types $\mathrm{x}$ subject groups, as shown in Table I $[\mathrm{F}(6,255)=16.53, \mathrm{P}<0.001]$. In the $\mathrm{NC}$ group, there is no significant difference in performance time between the four navigation map types $(\mathrm{P}=0.39)$. In the $\mathrm{MCI}$ group, the paper map had the longer performance time than north-up map, track-up map and colored lines guide $[\mathrm{F}(3,54)=10.41$, $\mathrm{P}<0.001]$. In the AD group, the track-up map and colored lines guide had the shorter performance time than the north-up map and paper map $[\mathrm{F}(3,36)=13.42, \mathrm{P}<0.001]$. Whatever the navigation map types, the $\mathrm{NC}$ group had the shortest performance time followed by MCI and AD.

Table I Wayfinding performances for the NC, MCI and AD groups under different navigation maps

\begin{tabular}{|c|c|c|c|c|c|c|}
\hline & \multicolumn{3}{|c|}{ Performance time } & \multicolumn{3}{c|}{ Number of wrong turns } \\
\hline & NC & MCI & AD & NC & MCI & AD \\
\hline North-up map & 109.54 & 129.72 & 187.37 & 0.25 & 1.90 & 2.85 \\
\hline $\begin{array}{c}\text { Track-up } \\
\text { map }\end{array}$ & 107.86 & 115.78 & 131.30 & 0.00 & 0.16 & 0.31 \\
\hline $\begin{array}{c}\text { Colored } \\
\text { lines guide }\end{array}$ & 107.05 & 119.25 & 141.60 & 0.02 & 0.11 & 0.31 \\
\hline Paper map & 112.15 & 167.16 & 228.88 & 0.30 & 2.42 & 3.77 \\
\hline
\end{tabular}

\section{B. Number of Wrong Turns}

The results of ANOVA test indicate that the navigation map types and subject groups had statistically significant main effects on number of wrong turns $[\mathrm{F}(3,255)=152.25, \mathrm{P}<0.001$; $\mathrm{F}(2,85)=76.03, \mathrm{P}<0.001$, respectively]. The track-up map (0.15) and colored lines guide $(0.14)$ had less number of wrong turns, followed by north-up map (1.66), and paper map
(2.17). NC group (.14) had the less number of wrong turns, followed by MCI (1.15) and AD (1.81).

The two-way interactions was were found for the performance time between the map types $\mathrm{x}$ subject groups, as shown in Table $\mathrm{I}[\mathrm{F}(6,255)=41.00, \quad \mathrm{P}<0.001]$. In the $\mathrm{NC}$ group, the track-up map and colored lines guide map had the less number of wrong turns than the north-up map and paper map $[F(3,165)=6.47, \mathrm{P}<0.001]$. In the MCI group, the track-up map and colored lines guide had the less number of wrong turns than the north-up map and paper map $[\mathrm{F}(3,54)=28.15$, $\mathrm{P}<0.001]$. In the AD group, the track-up map and colored lines guide had the number of wrong turns, followed by the northup map and paper map $[\mathrm{F}(3,36)=61.37, \mathrm{P}<0.001]$. Whatever the navigation map types, the NC group had the less number of wrong turns followed by MCI and AD.

\section{Discussion}

The performance time and number of wrong turns improved the most when subjects used the track-up map and colored lines guide. In all the systems we tested, the track-up map and colored lines guide showed better effect in facilitating wayfinding ability in all groups. According to some previous studies, AD impaired the ability to mentally rotate [18-20]. As a result, while using north-up maps, AD patients would miss the turning points or slow down because they couldn't mentally rotate the maps to unify with the maze [13]. Colored lines guide was a good design in developing electric maps for AD patients. Some previous studies found that colored lines guide has an effect on wayfinding performance in unfamiliar and complex hospital space [14]. The paper map was performed worst in all navigation maps, due to its full view, implying more information, heavier burden on attention and longer time needed to react. A possible interpretation would be that the AD patients with an impaired cognitive function were overloaded with too much information in the full view paper map.

\section{Conclusion}

Current navigation maps among related studies are designed generally for common people rather than for cognitive impaired patients. Our study proposed that track-up maps and colored lines guide could efficiently decrease number of wrong turns and performance time on wayfinding. Our result has provided insight to the development of future electric maps for cognitive impaired patients.

\section{Acknowledgment}

We would like to thank all of the subjects who participated in this study. This study was supported by the National Science Council (Taiwan) (NSC101-2221-E224-001MY2) and National Taiwan University Hospital, Yun-Lin Branch (NTUHYL101.N007).

\section{References}

[1] G.A. Satalich, "Navigation and wayfinding in virtual reality: Finding proper tools and cues to enhance navigation awareness," Master's Thesis, University of Washington, 1995. 
[2] L.E. Hebert, P.A. Scherr, J.L. Bienias, D.A. Bennett, and D.A. Evans, "Alzheimer's disease in the U.S. population: Prevalence estimates using the 2000 Census," Archives of Neurology, vol. 60, no. 8, pp. 1119-1122, 2003.

[3] A. Hofman, W.A. Rocca, C. Brayne, M.M.B. Breteler, M. Clarke, B. Cooper, J.R.M. Copeland, J. F. Dartigues, A.D.S. Droux, O. Hagnell, T.J. Heeren, K. Engedal, C. Joker, J. Lindesay, A. Lobo, A.H. Mann, P.K. Molsa, K. organ, D.W. 'Connor, R. ulkava, D.W.K. Kay, and L. Amaducci, "The prevalence of dementia in Europe: a collaborative study of 1980-1990 findings," International Journal of Epidemiology, vol. 20, pp. 736-748, 1991 .

[4] D.L. Bachman, P.A. Wolf, and R. Lin, "Prevalence of dementia and probable senile dementia of the Alzheimer type in the framingham study," Neurology, vol. 42, pp. 115-119, 1992.

[5] M.C. Tu, and M.C. Pai, "Getting lost for the first time in patients with Alzheimer's disease," Int Psychogeriatr, vol. 18, pp. 67-70, 2006

[6] R. McShane, K. Gedling, J. Keenw, C. Fairgurn, R. Jacoby, and T. Hope, "Getting lost in dementia: a longitudinal study of a behavioral symptom," Int Psychogeriatr, vol. 10, pp. 253-260, 1998.

[7] R.G.M. Morris, P. Garrud, J.P. Rawlins, J. O'Keefe, "Place navigation in rats with hippocampal lesions," Nature, vol. 297, pp. 681-683, 1982.

[8] R.S. Astur, L.B. Taylor, A.N. Mamelak, L. Philpott, R.J. Sutherland, "Humans with hippocampus damage display severe spatial memory impairments in a virtual Morris water task," Behav Brain Res vol. 132, pp. 77-84, 2002.

[9] D. Boyd, "Creating signs for multicultural patrons," The acquisitions librarians, vol. 9/10, pp. 61-66, 1993.

[10] L.A. Streeter, D. Vitello, S.A. Wonsiewicz, "How to tell people where to go: comparing navigational aids," International Journal of ManMachine Studies, vol. 22, pp. 549-562, 1985.
[11] S.T. Uang, and S.L. Hwang, "Effects on driving behavior of congestion information and of scale of in-vehicle navigation systems," Transportation Research Part C, vol. 11, pp. 423-438, 2003.

[12] G. Li, and S. Oliver, "The effects of electronic map and orientation on driver response time and error rate for road identification. In D. deWaard et al. (Eds)," Human-system interaction, pp. 293-302, 2000, Maastricht, the Netherlands: Shaker.

[13] W. Rodes, and L. Gugerty, "Effects of Electronic Map Displays and Individual Differences in Ability on Navigation Performance," Human Factors, vol. 54, no. 4, pp. 589-599, 2012.

[14] R. Passini, "Wayfinding: A conceptual framework," Man-Environment Systems, vol. 10, no. 1, pp. 22-34, 1980.

[15] J. Carpman, M. Grant, and D. Simmon, "Design that cares: Planning health facilities for patients and visitor," Chicago, I1: American Hospital Publishing, 1986.

[16] M.F. Folstein, S.E. Folstein, and P.R. McHugh, "Mini-mental state". "A practical method for grading the cognitive state of patients for the clinician,"J Psychiatr Res vol. 12, no. 3, pp. 189-98. 1975.

[17] C.P. Hughes, L. Berg, W.L. Danziger, L.A. Coben, and R.L. Martin, "A new clinical scale for the staging of dementia," British Journal of Psychiatry, vol. 140, pp. 566 -572, 1982.

[18] C. Rainville, N. Marchand, and R. Passini, "Performances of patients with a dementia of the Alzheimer type in the Standardized Road-Map test of Direction Sense," Neuropsychologia, vol. 40, pp. 567-573, 2002.

[19] T.T. Lineweaver, D.P. Salmon, M.W. Bondi, and J. Corey-Bloom, "Differential effects of Alzheimer's disease and Huntington's disease on the performance of mental rotation," J Int Neuropsychol Soc, vol. 11, pp. $30-39,2005$.

[20] L.J. Tippett, K. Blackwood, and M.J. Farah, "Visual object and face processing in mild-to-moderate Alzheimer's disease: from segmentation to imagination," Neuropsychologia, vol. 41, pp. 453-468, 2003. 